\title{
SIMULANDO EL SABER: LA SATURACIÓN EN LOS MUNDOS DE FICCIÓN LUDONARRATIVOS
}

\author{
SIMULATING KNOWLEDGE: SATURATION \\ IN LUDONARRATIVE FICTIONAL WORLDS
}

Luis NAVARRETE-CARDERO

Universidad de Sevilla

$\underline{\text { lnavarrete@,us.es }}$

Juan J. VARGAS-IGLESIAS

Universidad de Sevilla

jivargas@,us.es

Resumen: Este artículo se propone emplear la teoría de mundos ficcionales para entender la condición estructural de los mundos revelados y no revelados en el videojuego. Para ello se acudirá a los índices de saturación intensional, o grados de conocimiento y comprensión del universo representado alcanzable por un jugador ideal, que pueden observarse en seis títulos delimitados como objetos de análisis. Estos índices, basados en los tipos de textura que ofrece cada ejemplo, determinan las formas en que las distintas combinaciones articulan el alcance heurístico del jugador en las modalidades epistémica y deóntica. Con ello este artículo pretende encontrar una perspectiva estructural de la naturaleza narrativa de las simulaciones de mundos interactivos, estableciendo así bases a partir de las cuales formular apreciaciones de las intensidades particulares.

Palabras clave: teoría de mundos ficcionales, videojuego, Doležel, Genette, modalidades narrativas.

Abstract: This article intends to apply the fictional worlds theory to the understanding of the structural conditions of revealed and not revealed worlds in videogames. In order to do so, we will work with to intensional saturation indexes, or degrees of knowledge and comprehension of the universe reachable by an ideal player, as seen in the six games chosen as objects of analysis. These indexes, based on the texture types offered by each example, determine the ways in which the different combinations articulate the heuristic scope of the player in the epistemic and deontic modalities. By 
means of it, this article intends to find a structural perspective of the narrative's nature of interactive world simulations, establishing basis from which to outline the assessments of the particular intensities.

Keywords: fictional worlds theory, videogames, Doležel, Genette, narrative modalities. 
$\mathbf{I}$ ntroducción

La clásica disputa en el ámbito de la teoría del videojuego entre una ontología del medio, ora de carácter narrativo, ora de cariz lúdico, parece haber perdido fuerza a favor del subrayado de la capacidad del dispositivo videolúdico como generador de mundos de ficción ${ }^{1}$. Este consenso ha resultado de una evidencia irrefutable: no todos los videojuegos cuentan una historia pero sí todos ellos establecen un mundo de ficción; la diferencia entre historias y mundos de ficción ha sido explicada por Doležel con meridiana claridad (1999) ${ }^{2}$.

El trasvase de esta distinción al ámbito videolúdico encuentra notables conexiones con el presente estado de la narrativa. Así, lejos de cualquier espontaneidad, este hecho revela una vuelta de tuerca en la teoría de la ficción, donde se reclama la aparición de una teoría de la poiesis enfocada en la narratología. Dicho de otro modo, se solicita un traslado de la atención de la narración como historia a la narración como ficción en un nuevo emplazamiento que marida a la perfección con la actual condición expansionista y transmedia de la narrativa (Doležel, 1999: 9). Al margen de las posibles implicaciones del mercado en este hecho, esta solicitud se basa en la imposibilidad de escudriñar un asunto creativo, el de la invención de mundos ficcionales, a través de una gramática narrativa como hicieron antaño los formalistas rusos con las variantes del cuento (Prop, 2014), sin duda, un gesto propio de una narratología clásica. Tras esta operación de renovación y desplazamiento, la ficción queda englobada ahora en el amplio espectro creativo del paradigma de los mundos posibles, un modelo sin restricciones e inclasificable a través de un simple catálogo de categorías gramaticales.

Bajo esta nueva perspectiva del poder heterocósmico del videojuego, resulta necesario un acercamiento fenomenológico a la figura del jugador, testigo y agente al mismo tiempo del mundo ficcional, con el objetivo de analizar los diferentes modos en que es interpelado intensionalmente por la estructura del mundo. A pesar de la actual proliferación de trabajos sobre worldbuilding ${ }^{3}$ desde campos tan afines como los Media Studies o los Game Studies - por otro lado, asentados desde hace décadas en el ámbito literario- existe una clara desatención a los aspectos hermenéuticos e

\footnotetext{
${ }^{1}$ El término videolúdico para referirse a la expresión propia del videojuego es empleado por primera vez en Genvo, S. (2006). La game design de jeux vidéo. Approches de l'expression videoludique. Paris, L'Harmattan.

${ }^{2}$ Simultáneamente a Doležel, Schaeffer, J. M. (1999). Pourquoi la fiction? Paris, Seuil, trata los mismos temas pero con atención a la cibercultura y a otros dispositivos ficcionales distintos de la literatura, caso del videojuego.

${ }^{3}$ La bibliografía sobre mundos posibles, mundos de ficción y worldbuilding es extensa y variada ya que el tema de la ficcionalidad afecta a múltiples disciplinas de las ciencias naturales y humanas. En el caso de la teoría del videojuego en español, nos permitimos aconsejar la lectura de la obra de Planells, A. J. (2015). Videojuegos y mundos de ficción. Madrid, Cátedra, por suponer una puesta al día de la literatura científica sobre mundos posibles y mundos de ficción, así como una valiosa propuesta de extensión de la cuestión hacia los mundos ludoficcionales. Como hipotexto de la obra de Planells, y desde el ámbito literario, nos permitimos señalar el libro de Doležel, L. (1999). Heterocósmica. Ficción y mundos posibles. Madrid, Arco/Libros, también un texto elemental en la configuración de este artículo. Finalmente, señalamos el libro de Wolf, M. J. P. (2012). Building Imaginary Worlds. The Theory and History of Subcreation. New York, Routledge, una obra que nos introduce en los aspectos sustanciales de la creación de mundos imaginarios como una actividad humana necesaria.
} 
interpretativos que cognitivamente están presentes durante el acto de jugar; una aproximación a este hecho puede aclararnos cómo se produce la recepción del mundo ficcional por parte del jugador.

Es por ello que denominamos testigo al jugador de videojuegos, una suerte de émulo del sujeto que presencia y adquiere verdadero conocimiento sobre el mundo de ficción en el que tiene lugar el desarrollo del juego. Este mundo ficcional es una superestructura que no siempre queda definida claramente para el jugador y en cuya presentación pueden generarse zonas de significado indeterminado, o incluso vacío, que son completadas, con herramientas diversas, por este testigo. En consecuencia, en este proceso de testificación, a la vez un proceso interpretativo - sobre los hechos ausentes y, por tanto, desconocidos de ese mundo- y un proceso de autentificación - de los hechos presentes y, por tanto, conocidos de ese mundo-, puede sostenerse la necesidad de un compromiso performativo, fundamentalmente cognitivo, del jugador para saturar y suturar la distancia existente en el mundo ficcional entre lo determinado y lo indeterminado.

¿Cómo percibe el mundo fíccional el jugador? ¿Todos estos mundos ficcionales resultan evidentes para él? ¿De qué manera el mundo ficcional se interesa por éste? ¿Puede el jugador, en todos los casos, recuperar el significado implícito del mundo ficcional? ¿Existen gradaciones variables de conocimiento y comprensión sobre el mundo ficcional según el modo en que se produce su revelación para el jugador? Metodológicamente, la respuesta del presente artículo a estas y otras cuestiones similares, se estructura sobre la construcción de una taxonomía de los mundos ficcionales en función del conocimiento y la comprensión que la textura del juego deja alcanzar al jugador. Así, en la primera parte de este trabajo, titulada materiales, tratamos de establecer una tipología de los mundos de ficción desde la receptividad basada en los conceptos dolezelianos de modalidades narrativas, haciendo especial hincapié en las denominadas restricciones epistémicas y deónticas ${ }^{4}$, pero, sobre todo, centrándonos en la función intensional de la saturación. Este primer epígrafe se complementa con la relación de un corpus de videojuegos adecuado a cada una de las tipologías encontradas que, posteriormente, servirá de estudio de casos en el apartado analítico del artículo. Esta misión analítica le corresponde a la segunda y tercera parte del trabajo, tituladas mundos de ficción revelados y mundos de ficción no revelados. Su desarrollo explica en detalle la constitución de estas dos grandes bifurcaciones de los mundos ficcionales acometidas desde su recepción por parte del jugador.

\section{Materiales}

En los videojuegos narrativos nuestro conocimiento del mundo ficcional depende en gran parte de las restricciones epistémicas que encontramos en el progreso de la historia. Digamos que ambas instancias, mundo ficcional e historia, mantienen su independencia estructural pero establecen una relación cognitiva que podríamos catalogar de simbiótica. Aunque nos centramos fundamentalmente en esta conexión, cabe recordar ahora que una parte de la sutura cognitiva del mundo ficcional puede

\footnotetext{
${ }^{4}$ Doležel (1999: 170-194) distingue un total de cuatro modalidades narrativas según las reglas que fundan la condición intensional del mundo de ficción: epistémicas - relativas a las reglas culturales de un mundo posible-, deónticas -relativas a las reglas prescriptivas y de sanción-, aléticas -relativas a las reglas naturales-y axiológicas -relativas a las reglas en su dimensión valorativa, ética o moral-.
} 
vehicularse también por vías secundarias de menor importancia. En paráfrasis de Genette, el jugador puede reconstruir el universo ludoficcional a través de la paratextualidad -peritexto y epitexto, es decir, criterios editoriales de comercialización, reseñas críticas, presentaciones en festivales, demos- o la architextualidad -la relación genérica del videojuego y, por ende, su conexión con otros títulos similares- (Genette, 1989: 11-13). Sin embargo, nuestro interés por esta relación cognitiva es puramente intensional, es decir, generada por el sentido del juego en el acto de jugar ${ }^{5}$; en este espacio del significado, el conocimiento del mundo ficcional en los videojuegos narrativos tiene lugar fundamentalmente a través de la historia. Esa simbiosis podría definirse como un proceso escalado donde la historia informa al jugador sobre el mundo ficcional y el mundo ficcional solicita, figuradamente, una acción reconstituyente al jugador en aras de lograr su propia saturación. Definimos este proceso seguidamente.

Muchas historias narradas por videojuegos parten de situaciones apocalípticas, presentan al personaje principal con problemas de memoria o, directamente, nos sitúan en un mundo, en primera instancia, extraño e inexplicable. Este punto de partida se ha convertido en un lugar común de la ficción videolúdica y vive ajeno a la naturaleza configurativa del mundo, es decir, resulta un comienzo habitual para muchos juegos tanto si el mundo ficcional está provisto de simplicidad-máxima aproximación al mundo real-o de transcendencia -desconexión variable del mundo ficcional con el mundo real por motivos fantásticos, tecnológicos, etc.- (Schell, 2015: 306). Estos ardides posibilitan la conformación del juego como un bildungspiel ${ }^{6}$ y ponen en marcha un proceso graduado de anagnórisis que desemboca en la comprensión de la historia y en la saturación del mundo ficcional. En la Poética, Aristóteles definió el proceso de anagnórisis - denominado reconocimiento- como aquel que lleva al personaje de un estado de desconocimiento - de cariz identitario, familiar o situacional- a otro de descubrimiento, es decir, es una transición de la ignorancia a la verdad (1988: 17). Nótese cómo el conocimiento o información del que hablamos concierne estrictamente al nivel diegético-ficcional. Sin embargo, resulta obvio que todo videojuego encierra igualmente un proceso de descubrimiento que afecta a las reglas del juego. Como veremos más adelante, en algunos casos ambos fenómenos pueden fundirse cuando la comprensión de una regla del juego es al tiempo una revelación sobre la constitución de su mundo ficcional. Este hecho es más común en juegos provistos de transcendencia.

La anagnórisis guarda estrechos vínculos con lo que Doležel denomina, dentro de las modalidades narrativas, restricciones epistémicas: «La historia con un secreto es un caso particular de búsqueda epistémica, una narración cuya base modal es la transformación de la ignorancia o la falsa creencia en conocimiento» (1999: 188). En su mayoría, las historias de videojuegos pueden concebirse como una búsqueda epistémica, independientemente del valor, poder y número de secretos pergeñados

\footnotetext{
${ }^{5}$ Como afirma Doležel, el autor construye el mundo de ficción mediante componentes, formas y estructuras y el lector lo reconstruye generando un sentido para esos elementos. A la operación de la autoría la denomina extensión y a la del lector intensión.

${ }^{6}$ El término, de invención propia, es una transformación del concepto de Bildungsroman o novela de aprendizaje, un tipo de relato construido sobre el proceso de madurez del personaje como acumulación lineal de conocimiento en una serie de intentos y errores (Doležel, 1999: 188).
} 
por la trama. Pero en su totalidad, sin excepción, todos los videojuegos suscitan esta búsqueda por parte del jugador en aras de satisfacer su deseo de completar el significado del mundo ficcional. A la medida de esta pulsión, un horror vacui mental, la denominamos saturación y, en mayor medida que la información suministrada por la historia, su conocimiento casi siempre es inferido y supuesto. Antes de explicar este concepto, son pertinentes algunas aclaraciones sobre la compleción del mundo ficcional y la abducción, ésta última como base del pensamiento que el jugador proyecta en el juego durante el acto de jugar.

Como primera aclaración, según nos advierte Doležel, el carácter incompleto de los mundos ficcionales es una propiedad derivada de su naturaleza de construcción humana. Esos huecos, «textura cero» en palabras del autor (1999: 242), son variables y se extienden por diferentes puntos de la textura explícita -elaborada por la autoría del videojuego-. Para Iser, que concibe el control del texto -sea literario, videolúdico, fílmico- sobre el acto de lectura: «El proceso de armar el significado de un texto no es algo privado porque, aunque moviliza la disposición subjetiva del lector, no conduce al ensueño sino al cumplimiento de las condiciones que ya han sido estructuradas en el texto» (1978: 49-50). Sin embargo, la textura cero escapa a dicho control del texto, sencillamente porque no es texto, poniendo en manos de la imaginación del jugador la compleción del significado del mundo fíccional; rellenar los huecos es, por tanto, un acto subjetivo que provoca realizaciones que no pueden ser comparadas sencillamente porque son diferentes (Doležel, 1999: 243). A pesar de que la compleción del mundo ficcional resulta un imposible, no podemos olvidar que determinadas franquicias de mundos de ficción -Star Wars, Star Trek, Uncharted, etc.- aprovechan esta propiedad para generar una ilusión de compleción. Este fenómeno justifica, no sólo la pervivencia de la franquicia, sino también la subcreación vicaria que muchos fanes acometen prolongando la expansión del mundo a través de prácticas consignadas como fandom (Wolf, 2012: 39).

Pero, al margen de esta última cuestión, ¿cómo se rellenan los huecos existentes en la textura? $\mathrm{O}$, de otra manera, ¿puede eliminarse la textura cero? Si la textura toma forma de contenido implícito -como veremos es posible la transfiguración de contenido implícito en textura cero, pero no al revés, es decir, es recuperable por el jugador a través del conocimiento de la textura explícita, podemos reconstituir el significado del mundo ficcional mediante la interpretación. Sin embargo, el proceso interpretativo conlleva la imposición de un determinado significado -el que sea, como bien sabemos por la función crítica- más que su recuperación. En este caso, el problema se resuelve mediante la inferencia, un acto de la razón que el lector/espectador/jugador realiza a partir de una preposición para deducir una nueva. Este procedimiento de inferencia, basado en la búsqueda del significado de lo indeterminado a partir de lo determinado y explícito, se denomina presuposición. Aunque operativamente la interpretación y la presuposición son diferentes, pues la primera impone un significado mientras que en la segunda deviene un significado, los resultados finales de ambos procesos están sujetos a la incertidumbre. Así, si no podemos confirmar la validez de una interpretación porque ésta puede ser sustituida por otra, tampoco podemos afirmar rotundamente la certeza de una presuposición puesto que requiere un conocimiento enciclopédico del mundo ficcional $-\mathrm{o}$ de los 
mundos ficcionales si se trata de una obra de género- que es variable de jugador a jugador en función de su capital cultural, conocimiento previo del medio, expectativas, etc.

Por tanto, y como segunda aclaración, gran parte de nuestras presuposiciones sobre el mundo ficcional de un juego están basadas en un procedimiento lógico y, en consecuencia, poseen una base cognitiva que puede definirse como un proceso silogístico. Si bien determinados autores han definido la base del acto del juego - el propio play - como un proceso abductivo (Navarrete et al., 2014), hemos de indicar que en la construcción de la historia y en la institución del mundo ficcional del juego por parte del jugador, caben los tres tipos de inferencia conocidos, es decir, la deducción, la inducción y la abducción. Esto es así sencillamente porque la comprensión de la historia y su progresión, y gran parte del mundo ficcional y su revelación, no pueden basarse exclusivamente en procesos abductivos, altamente inciertos, necesitando ambos anclar un significado unívoco mediante las inferencias deductiva e inductiva. De otro modo, el jugador jamás abandonaría el espacio de la incertidumbre.

Siguiendo a Doležel, y teniendo en cuenta estas dos aclaraciones, estamos en disposición de definir la función intensional de la saturación de un mundo ficcional. Todo videojuego posee una determinada densidad, esto es, una distribución de su textura explícita, implícita y cero: «La textura explícita construye el dominio determinado, la textura implícita el dominio indeterminado y la textura cero el dominio de los huecos» (1999: 258). La saturación por tanto es variable y supone un desafío para el jugador, un reto inversamente proporcional que aumenta al tiempo que esta disminuye. El grado de dificultad en la comprensión, asimilación y reconstrucción de un mundo ficcional está estrechamente ligado a la densidad de su saturación.

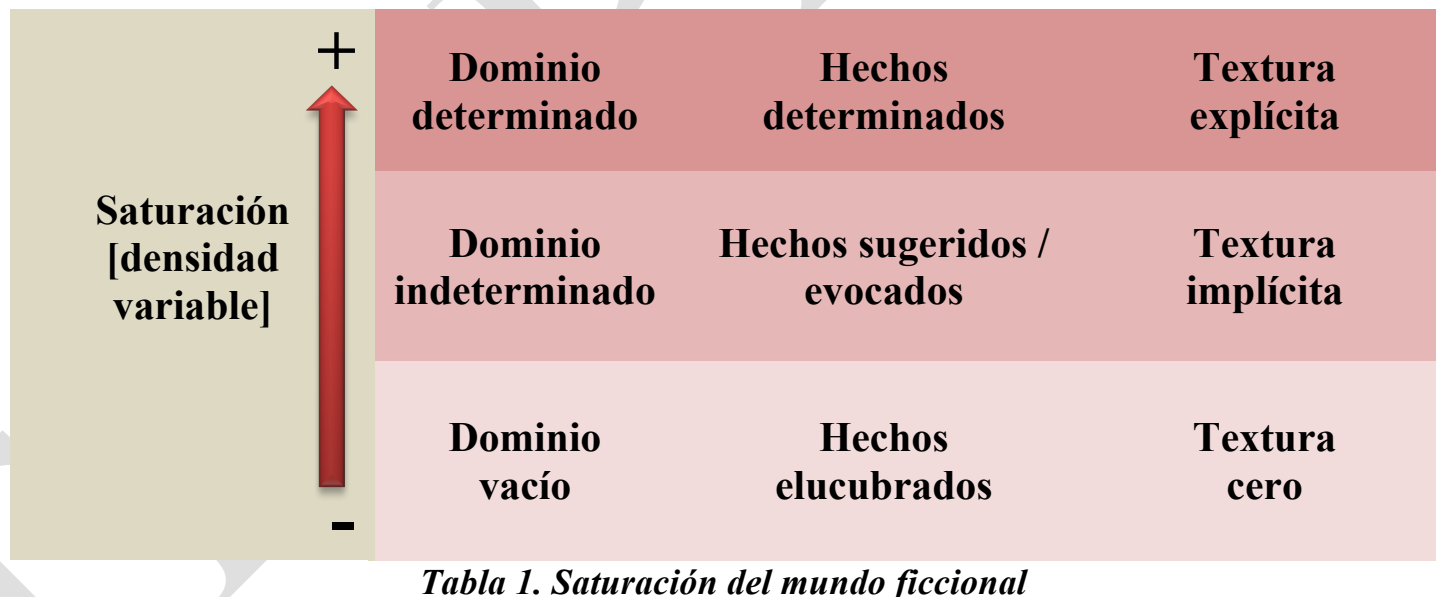

Por tanto, partiendo de la densidad variable de la saturación, presentamos una escisión de los mundos ficcionales videolúdicos en dos tipologías diferentes. Es evidente que algunos tipos de mundos se ven connotados por fuerzas que emanan de la textura del juego - es decir, derivadas de su construcción autoral- o por negligencia del jugador en al acto del juego -es decir, por inacción del jugador-. Las primeras, de carácter estructural, resultan ineludibles e impuestas al jugador; la segunda, de naturaleza subjetiva, es subsanable en un alto porcentaje de videojuegos narrativos. Por ejemplo, un juego como Amnesia: The Dark Descent (Frictional Games, 2010) en primera instancia, y por 
construcción autoral, erige los significados de su historia y de su mundo ficcional sobre hechos determinados e indeterminados -tanto de textura explícita como implícita- conocidos mediante un progreso lineal de anagnórisis que desemboca en uno de los finales previstos. Sin embargo, por negligencia del jugador, muchos de los $\operatorname{artefactos}^{7}$ del juego resultan eludidos, generándose, por su inacción, una disminución de la densidad de la saturación del juego que transforma gran parte de sus texturas explícita e implícita en textura cero. Los juegos cuya historia y mundo de ficción son recuperables a partir de la textura que se deja alcanzar al jugador -más allá de que éste la eluda voluntariamente- los hemos denominados mundos de ficción revelados. Dentro de los mundos de ficción revelados, el proceso de anagnórisis puede seguir un doble camino. Habitualmente, en juegos narrativos de progresión, la anagnórisis es un proceso lineal hacia el conocimiento del jugador; en juegos de retórica procedural, el proceso de anagnórisis se produce ipso facto en una fase indeterminada del juego -antes o después, dependiendo del jugador-poniendo fin, es decir, dando por completado, el proceso de conocimiento del mundo ficcional por parte del jugador.



Tabla 2. Mundos ficcionales revelados en función de la construcción autoral, la negligencia del jugador y el modo de anagnórisis

Por otro lado, hemos denominado mundos de ficción no revelados a aquellos mundos establecidos por juegos cuya textura por construcción autoral no deja alcanzar al jugador un conocimiento lógico sobre el mundo de ficción. Por defecto, esta tipología de mundo ficcional se construye deliberadamente sobre textura indeterminada acompañada de grandes huecos de textura cero. En estos videojuegos, el proceso de anagnórisis es igualmente incompleto y raramente existe negligencia del jugador por inacción ya que los artefactos no son comunes y los existentes resultan de consulta obligatoria. Estos mundos de ficción reclaman las herramientas de la interpretación y de la presuposición para su saturación, estableciendo límites confusos con ciertas propuestas videolúdicas con una clara disposición poética.

\footnotetext{
${ }^{7}$ Para una introducción a la terminología sobre la escritura de la narrativa videolúdica, véase Bateman, C. (ed.) (2007). Game Writing Narrative Skills for Videogames. Course Technology, Boston MA.
} 


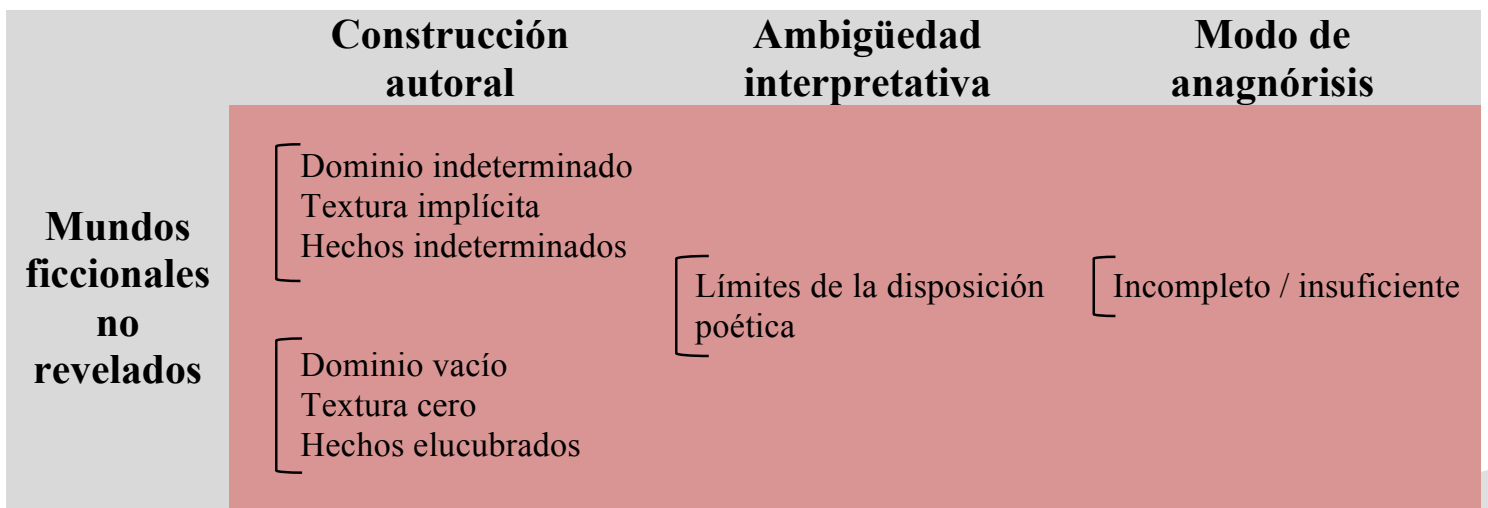

Tabla 3. Mundos ficcionales no revelados en función de la construcción autoral, la ambigüedad interpretativa del jugador y el modo de anagnórisis

Finalmente, de cara a la aplicación práctica de los materiales descritos, hemos establecido un corpus de videojuegos que nos permitirá calibrar la utilidad de estos a través de una serie de estudios de casos escindidos en las dos grandes tipologías señaladas, mundos de fícción revelados y mundos de ficción no revelados. Es cierto que en esta selección parece producirse un apriorismo, un descendimiento a los efectos sin haber concretado la causa, pero sólo es un espejismo resultante de la exposición de los hechos aquí investigados. Hemos decidido analizar una tríada de videojuegos para cada una de las clasificaciones de mundos ficcionales indicadas; el proceso analítico se complementará con la aparición de nuevos conceptos que nos ayudarán a segmentar y describir con mayor acierto cada uno de los casos en función de sus peculiaridades, al margen de que estén englobados bajo la misma etiqueta de mundo ficcional revelado o mundo ficcional no revelado. El corpus es el siguiente.

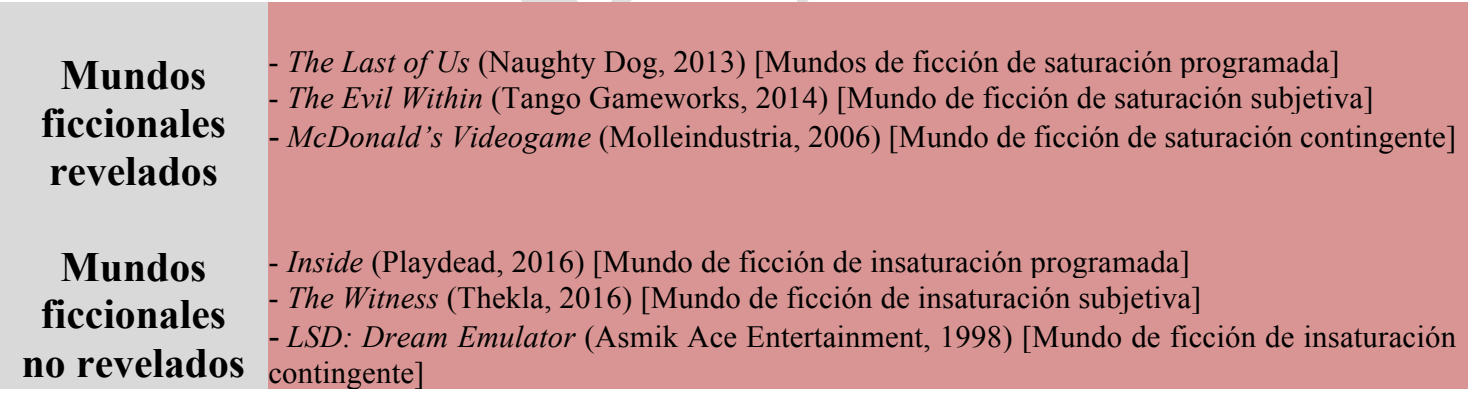

Tabla 4. Corpus de videojuegos seleccionados escindido por tipología de mundo ficcional

\section{Mundos de ficción revelados}

Penetramos en el análisis de los mundos de ficción revelados de la mano de tres videojuegos sobradamente conocidos. En muchas ocasiones la teoría del videojuego se construye sobre ejemplos escasamente comerciales, juegos desconocidos o inasequibles en los que es imposible calibrar con exactitud el proceso de adecuación entre los argumentos teóricos y la naturaleza del juego analizado. Si se nos permite la apostilla, es como si la historia del cine se hubiera construido sobre películas invisibles. Una aclaración final antes de comenzar este recorrido. A excepción de McDonald's Videogame (Molleindustria, 2006), que presenta ciertas novedades en la configuración de sus texturas explícita e implícita, derivadas de su complexión procedural, somos conscientes de las similitudes de 
los dos primeros casos, The Last of Us (Naughty Dog, 2013) y The Evil Within (Tango Gameworks, 2014), hasta el punto de que el segundo puede considerarse un caso especial del primero. Sin embargo, existen pequeñas diferencias en la función de saturación del mundo ficcional de cada uno de estos ejemplos que merecen la pena ser destacadas.

\section{Mundos de ficción de saturación programada. The Last of Us}

En septiembre de 2013, una pandemia ocasionada por una cepa del hongo Cordyceps devasta el mundo conocido. Este hongo mutante se caracteriza por transformar a sus huéspedes humanos en engendros irracionales antropófagos, conocidos como infectados. En los suburbios de Austin, Texas, Joel intenta escapar del caos reinante junto a su hermano Tommy y su hija Sarah. Durante su huida, un soldado dispara a Sarah, que acaba muriendo en brazos de su padre. Veinte años después del brote inicial, la infección ha acabado con la mayor parte de la civilización humana. Los supervivientes se han visto obligados a buscar refugio, bien en zonas de cuarentena bajo ley marcial fuertemente vigiladas, o bien en asentamientos independientes; otros han optado por formar grupos nómadas. Joel trabaja ahora como contrabandista con su socia y pareja, Tess, en la zona de cuarentena ubicada en el North End de Boston, Massachusetts. Ambos contrabandistas deciden dar caza a Robert, un traficante del mercado negro, con el objetivo de recuperar un cargamento de armas que éste les ha robado. Antes de que Tess lo asesine, Robert confiesa que ha vendido el cargamento a los Luciérnagas, una organización rebelde en guerra contra el directorio militar que ha sustituido al gobierno federal estadounidense. La líder de los Luciérnagas, Marlene, les ofrece a Tess y Joel un cargamento de armas dos veces mayor como compensación por la pérdida del original. A cambio, ambos deben escoltar a una chica adolescente, llamada Ellie, hasta un grupo de Luciérnagas escondidos en la Casa del Estado de Massachusetts, fuera de la zona de cuarentena.

Algunos de los eventos narrados en este resumen se han conformado en el juego como textura implícita que ha sido recuperada gracias a un proceso de inferencia basado en la presuposición. Así, el rol de los Luciérnagas durante el desarrollo del juego nunca dejará de ser una incertidumbre si el jugador no presupone la labor de estos como la de un sustituto en el exilio -es decir, en las zonas de poder, geográficamente bien diferenciadas en el mapa de este nuevo mundo- del gobierno burocrático y federal del país. En el actual estado marcial de los Estados Unidos -hablamos del mundo ficcional del juego-, el nuevo directorio militar ha desertado de sus labores cívicas y sociales, preocupándose en exceso por el control poblacional, es decir, imponiendo un nuevo código deóntico afín a su propia complexión pero obviando tareas esenciales para la reinstauración del mundo anterior como la investigación científica, una luz ahora portada por estas luciérnagas rebeldes. Por tanto, la revelación de la textura implícita de este asunto matriz puede llevar al jugador a dominios inexplorados donde, además de una lucha del hombre por la supervivencia en un mundo físicamente hostil, el juego le habla sobre un golpe de Estado que ha dibujado los límites de un nuevo Estados Unidos totalitario que no quiere dejar de serlo. Este hecho nos conduce a terrenos aún más lejanos si tenemos en cuenta el resultado de la relación de Joel y Ellie con ese gobierno exiliado, una estructura igualmente basada en 
la fuerza y la represión. Más que una lucha por el bien común a la búsqueda de la generación de una vacuna, los Luciérnagas en The Last of Us sostienen una guerra por la recuperación de sus viejas estructuras de poder. Y Ellie es su pasaporte al pasado.

La estructura textural del videojuego se reparte a través de un clásico modelo de collar de perlas con alguna que otra novedad. Así, podemos escindir la densidad de la saturación del mundo ficcional en tres partes bien diferenciadas. Por un lado encontramos las cinemáticas -cutscene-, configuradas casi siempre como textura explícita debido a su obligatorio rol funcional como explicación o introducción de la parte lúdica. Éstas no toleran la presencia de la indeterminación, hecho que sucede siempre cuando existe textura implícita, porque su mensaje deber ser unívoco para evitar confusiones en el jugador sobre cómo actuar o, en otro caso, para otorgar sentido al segmento lúdico precedente. En segundo lugar aparecen las partes lúdicas, normalmente en forma de desafío agónico acompañadas de mecánicas de combate o sigilo. Durante su desarrollo, el jugador puede encontrar artefactos o coleccionables que le informan sobre el mundo ficcional. Finalmente, en este título aparece una nueva sección interlúdica de gran importancia para el despliegue de la textura implícita. Se trata de los momentos donde Joel y Ellie caminan juntos con el objetivo de cumplir alguna búsqueda epistémica que permita el progreso de la historia -un espacio, un personaje, un objeto-. En estos momentos, además del hallazgo de munición, comida, botiquines, artefactos, coleccionables o piezas para armas, el jugador puede mantener conversaciones con su acompañante con segmentos activables a voluntad $\mathrm{y}$, por tanto, eludibles. La configuración de la textura implícita en este videojuego merece un comentario detallado.

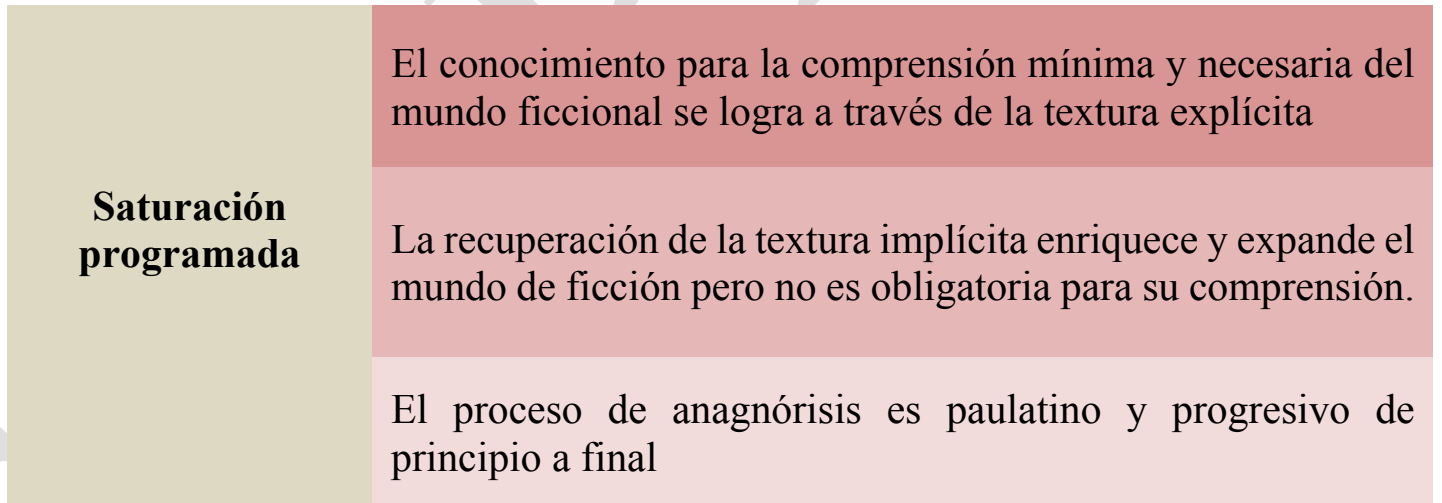

Tabla 5. Saturación programada.

Ciertamente, la textura implícita en un videojuego no sólo puede emular el modus operandi de otros medios narrativos, como la novela o el cine, donde lo implícito sólo puede vivir oculto en la sugerencia de la explicitud de la palabra o de la imagen, sino que además, gracias a la interacción del jugador con el espacio del juego, lo implícito adquiere un carácter azaroso unas veces o voluntario y, por tanto eludible, otras. Del mismo modo que una película o una novela pueden sembrar tejido implícito en la textura explícita a través de la palabra dialogada o de la narración de los eventos - su potencia dependerá de la focalización del narrador-, un videojuego como The Last of Us trabaja de 
manera similar gran parte de la revelación de su textura implícita. Así, la relación de Joel y Tess, algo más que una relación de trabajo; el pasado de ésta, al parecer bastante truculento; la amistad entre Marlene y Tommy, rota en el presente de la historia; la historia de amor entre Bill y su pareja, con un trágico final; o la amistad pasada entre Bill y Joel, donde se fraguaron compromisos que afectan a su relación actual, etc., conforman una gran superficie de textura implícita que ha sido sugerida, mayoritariamente, a través de los diálogos de los personajes. Sin embargo, el videojuego posee además un modo único de trabajar la textura implícita gracias a la interactividad del jugador, un método que debe ser prediseñado por la autoría del videojuego en un caso exclusivo de narrativa espacial. Nos referimos a toda esa información en forma de artefactos, objetos varios, coleccionables, etc., que pueden otorgarnos un conocimiento más denso sobre la historia y su mundo ficcional. Como hemos indicado, muchos de ellos llegan a nosotros azarosamente, porque se encuentran sin más sobre la mesa detrás de la que estamos escondidos, mientras que otros pueden ser buscados con ansia por el jugador o simplemente eludidos, relegados definitivamente al abismo de la textura cero. Aunque el cine también construye una narrativa espacial, el espectador no puede negar nunca la recepción de un nuevo conocimiento, a no ser que cierre sus ojos para no ver o ignore el significado oculto de lo que la cámara le muestra.

La textura cero en The Last of Us, es decir, aquellos espacios huecos sobre los que no tenemos información y, por tanto, son imposibles de presuponer lógicamente mediante un proceso cognitivo, son tres en nuestra opinión. De dos de ellos se ha realizado una expansión en forma de contenido descargable titulado The Last of Us: Left Behind (Naugthy Dog, 2014), incluido finalmente como parte de la versión remasterizada del título original. En esta expansión, o saturación de dos grandes huecos de la textura cero del juego matriz, conocemos la historia de Ellie y Riley, donde se desvelan datos sobre la vida pasada de la chica -amistad, sentimientos, inclinación sexual-además de la muerte de su amiga o cómo se produjo su propia infección y, en montaje alternativo, vemos los esfuerzos de Ellie por salvar la vida de Joel, gravemente herido tras el encuentro con varios miembros de la comunidad antropófaga dirigida por David. El montaje entre ambas porciones de lo que antes era textura cero, escindido por cortes a negro que nos informan sobre el cambio de cronotopo del videojuego, sugieren $\mathrm{y}$, en consecuencia, conforman, implícitamente, un nuevo hecho evocado: el hueco afectivo dejado por la muerte de Riley en la vida pasada de Ellie ha sido ocupado ahora por Joel. Mientras, el otro gran vacío o textura cero del juego, los veinte años transcurridos desde la muerte de Sarah hasta el encuentro de Joel con Ellie, aún permanecen en la oscuridad.

Hemos optado por denominar saturación programada al modo en que The Last of Us nos presenta la relación entre los dominios de lo determinado, lo indeterminado y lo vacío. Por programada entendemos la saturación diseñada por la autoría, mediante textura explícita, que asegura un conocimiento mínimo para la comprensión de la historia y del mundo ficcional. El proceso de anagnórisis es paulatino y se desarrolla de principio a final del juego. La consecución de este logro se alcanza por factores intrínsecos, es decir, a través de una buena ejecución de la forma ludonarrativa del juego, y por motivos extrínsecos, o sea, por la relación y experiencia que previamente el jugador 
tiene con el mundo ficcional del juego o con otros mundos parecidos. Así, en primera instancia, todo jugador parece poseer un conocimiento aceptable sobre mundos apocalípticos zombis o pandémicos, algo que no ocurre con nuestro siguiente juego, The Evil Within, una aventura en tercera persona diseñada por Shinji Mikami.

\section{Mundos de ficción de saturación subjetiva. The Evil Within}

La acaudalada familia Victoriano, de Krimson City, está compuesta actualmente por Ernesto, Beatriz y sus hijos, Laura y Rubén. Siguiendo los dictados de su posición, el clan mantiene una estrecha relación con el hospital psiquiátrico Beacon, cimentada sobre donativos a nombre del Dr. Marcelo Jiménez, y con la iglesia local, de la que el paterfamilias es un reputado miembro. Sin embargo, Rubén detesta la corrupción eclesiástica y resulta ser un prodigio en materia científica, en los campos de la biología y de la psicología. El Dr. Jiménez se muestra interesado por sus rudimentarios pero inquietantes experimentos, ofreciéndole ayuda para mejorar sus resultados.

Los campesinos, rebelados contra los Victoriano por las tácticas de apropiación de sus tierras, incendian los campos de cultivo quemando el granero donde Rubén y Laura pasan la tarde jugando. La niña salva a su hermano pero muere calcinada. Rubén, desfigurado por las quemaduras, es confinado por su padre en el sótano de la casa. Varios años después, éste consigue escapar, heredando la fortuna familiar tras asesinar a sus padres.

Con ayuda del doctor Jiménez, el joven continúa su trabajo sobre la mente humana, decidido a transferir su conciencia a un cuerpo nuevo. A sus espaldas, el médico se apropia de los resultados de la investigación; con su publicación atrae la atención de Mobius, una organización secreta de origen desconocido que a partir de ahora financiará los experimentos de ambos. El objetivo de Rubén es la construcción de STEM, un artilugio diseñado para conectar diferentes mentes humanas que permite compartir sensaciones y recuerdos a nivel bioquímico. Mobius se apropia del prototipo y elimina a Rubén, salvaguardando el cerebro, elemento clave que impulsa STEM mediante sus ondas cerebrales. Sin embargo, la conciencia de Ruvik - antes Rubén Victoriano- sigue existiendo dentro de la máquina, convirtiéndose en malvado demiurgo del mundo misceláneo generado por el dispositivo mediante la interconexión de todas las mentes que una vez fueron utilizadas en la experimentación. El detective Sebastián Castellanos debe investigar un homicidio múltiple en el hospital Beacon. Castellanos es un buen policía perseguido por la muerte de su familia.

Todos los hechos narrados en este resumen están configurados como textura implícita por la autoría del videojuego. Como hemos visto anteriormente, la textura implícita en los videojuegos puede recuperarse por medios tradicionales -diálogos, información del narrador, acciones de los personajes, etc.- o por procesos exclusivos erigidos sobre la interacción con el espacio del juego que atañen sólo al jugador -azarosos y voluntarios-. A diferencia de The Last of Us, la zona de textura explícita en el juego de Mikami es realmente menor, estrechándose hasta cubrir sólo la parte lúdica del juego. En este caso, las cinemáticas parecen irrelevantes para el proceso de anagnórisis a pesar de ser textura explícita. Ciertamente, la estructura de su saturación posee una distribución similar a la del juego de 
Naughty Dog pero evidenciando una notable disminución del dominio de lo determinado. ¿Un juego narrativo de progresión donde el dominio de lo determinado se corresponde exclusivamente con la parte lúdica?

Según creemos, existen dos razones que justifican este hecho. Por un lado, quizás inconscientemente, se vislumbra un respeto del diseñador hacia el ludus, escindido claramente de la parte narrativa del título. Por otro, esta considerable ampliación de lo indeterminado, parece coincidir con la configuración del juego como un survival horror, un dispositivo psíquico que, como la novela o el cine de terror, se expresa mejor en el terreno de lo incierto que en el dominio de lo explícito.

Respecto a la primera consideración, es evidente que con ella la autoría del videojuego deja en manos del jugador la decisión de otorgar valor narrativo al juego -convertirse en testigo - o simplemente recorrer su parte explícita, es decir, habitar el nivel lúdico. Si el jugador opta por esta última vía, su vivencia reduce el juego a su pura esencia, o sea, a un proceso objetivo conformado por diferentes niveles donde el jugador adquiere experiencia y destreza para combatir a distintos enemigos que se oponen en su camino hacia la consecución de la meta final. La diversión y la emoción del jugador están garantizadas. Sin embargo, si el jugador opta por la primera vía, puede transcender esta esfera de lo objetual profundizando en aquello que subjetivamente hace humano a un juego, es decir, su valor narrativo. El despliegue emocional en este caso es bien distinto del anterior; a la emoción pura del juego se añaden otras exclusivas del dominio del sujeto. La empatía, el miedo o el respeto por los personajes y enemigos -antes sólo objetos incapaces de estas proyecciones- convierte el juego en otra experiencia distinta. Si el jugador se decide por esta opción, le espera un duro camino recorrido por una extensa textura implícita en forma de artefactos y visionado de fantasmagóricas escenas del pasado donde conocerá la historia de Sebastián, las dudas sobre Jill Kidman -también textura cero que desemboca en dos expansiones descargables, The Assignment (Tango Gameworks, 2015) y The Consequence (Tango Gameworks, 2015)-, la fragilidad de Joseph, la oscura labor de Mobius, la mezquindad de Jiménez, etc. Nada de esto vive en la parte explícita del juego, es necesario zambullirse voluntariamente en el dominio de lo implícito para conocerlo.

La decisión de Mikami de reducir la textura explícita del juego a su vertiente lúdica dejando en manos del jugador la elección de su propio rol, jugador o sujeto, elimina algunas disonancias narrativas presentes en The Last of Us, por otro lado lugares comunes de muchos videojuegos de mundos de ficción revelados. Casi al final del título americano, Joel busca desesperadamente a Ellie después de que la chica haya huido a caballo, refugiándose en una casa apartada. La desesperación impresa en Joel, mostrada por la textura explícita -a través de diálogos, en su busca Joel va acompañado de Tommy, y cinemáticas- del juego y causada por el deseo de encontrarla, queda rota en la parte lúdica cuando el jugador - cosificando a los personajes, es decir, desposeyéndolos de su naturaleza de sujetosprefiere inspeccionar todas las estancias de la casa para recolectar recursos antes que subir a reconfortar a Ellie. Este fenómeno disonante ha sido desterrado del juego de Mikami gracias a su naturaleza binaria y dual. 


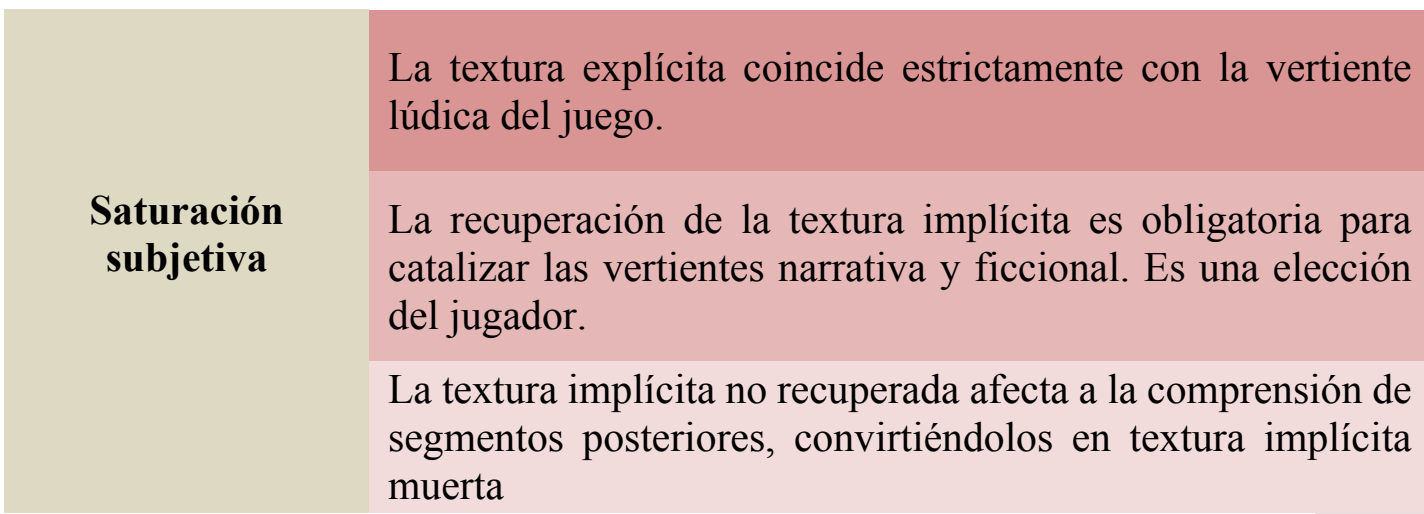

Tabla 6. Saturación subjetiva

Denominamos, por tanto, saturación subjetiva a aquella en la que el jugador puede escoger su propio destino en el juego, marcado por naturalezas excluyentes pero que pueden ser complementarias. A diferencia de la saturación programada, la saturación subjetiva no deja la comprensión de la historia o del mundo ficcional en manos de la textura explícita, no existe un mínimo de información obligatoria recibida por el jugador que le haga partícipe del proceso de anagnórisis. Esta decisión le corresponde sólo a él. La narrativa y el mundo de ficción de The Evil Within son extraordinariamente sugerentes pero también muy complejos. Urgen de un compromiso mayor por parte del jugador que en el caso anterior, hasta el punto de rozar la ininteligibilidad si el testigo, en un acto de flaqueza, decide obviar la recuperación de ciertos segmentos de información acumulada en la parte indeterminada, un gesto que condenará para siempre a su textura implícita a la región de la textura cero. Si hablamos con propiedad, el título de textura cero para este caso es incorrecto, ya que la textura cero simplemente no es textura. Sólo la rejugabilidad del título puede devolver la vida a esa estructura que aun estando presente es al mismo tiempo una ausencia.

\section{Mundos de ficción de saturación contingente. McDonald's Videogame}

Hacer dinero en una empresa transnacional no resulta fácil. Detrás de cada hamburguesa hay un largo y articulado proceso que el jugador tendrá que aprender a gestionar. McDonald's, como todas las modernas corporaciones, deslocaliza la producción en varios lugares del mundo. La tarea del jugador es tener bajo control los cuatro sectores que intervienen en la producción: el sector agrícola, la granja de engorde de los animales, el local donde se dispensa la comida rápida $\mathrm{y}$, por último, el cuartel general de la multinacional.

Leyendo este resumen, nada haría pensar al jugador que está frente a una «satirical business simulation» (Molleindustria, 2018). En primera instancia, el mundo de ficción presentado por este pequeño juego es lo que Schell denomina un mundo de ficción caracterizado por la simplicidad (2015: 306-307) o Doležel un mundo donde las modalidades del mundo real determinan lo que es posible, imposible y necesario en el mundo ficcional, es decir, un mundo de ficción natural (1999: 173). El proceso de anagnórisis parece entonces encaminado de forma lineal hacia la comprensión y reconocimiento por parte del jugador del desempeño habitual de una empresa multinacional de comida 
rápida. Sin embargo, durante el acto del juego, el jugador descubrirá súbitamente que el mundo de ficción natural que McDonald's Videogame propone es un mundo de ficción natural alternativo, otra posibilidad, de ese mundo que naturalmente conocemos, tamizada por otro punto de vista ideológico opuesto al ofrecido al gran público por el marketing de las grandes compañías. En ese momento, el jugador se sabrá engañado por el proceso de anagnórisis que pensó seguir, dándose cuenta repentinamente -en un momento indeterminado del juego- que el proceso de reconocimiento de esta realidad le ha revelado de manera ipso facta una nueva forma de asomarse a los mundos de ficción creados por estas gigantescas corporaciones. Antes de concluir este razonamiento, nos permitimos una breve explicación del funcionamiento de los juegos procedurales.

La pregunta clave que domina este tipo de discursos videolúdicos es ¿qué problemas puede iluminar el videojuego? Uno de los géneros que mejor sintoniza con esta pulsión social es el denominado Newsgames, un tipo de juego con propósito informativo vinculado a la actualidad cuyo origen se sitúa en September 12th (Newsgaming, 2003). En líneas generales, estos juegos han desembocado en otras praxis lúdicas diseñadas para concienciar sobre los derechos y deberes ciudadanos, la denuncia de situaciones de injusticia, la inserción de propuestas educacionales y medioambientales, etc. Muchos de estos Serious Games utilizan una retórica procedural. Ésta acentúa el principio de simulación propio de los videojuegos y otorga máxima libertad al diseñador para la creación del significante del juego.

Partiendo de la definición de las propiedades esenciales de los artefactos digitales esbozada por Murray en Hamlet on the Holodeck (Murray, 1997), Bogost evidencia cómo los videojuegos trabajan en virtud de la ejecución de una serie de procesos programáticos (Bogost, 2007: 4). Este proceduralismo no es una práctica exclusiva de los ordenadores; nuestras sociedades ponen en marcha multitud de procesos: el proceso judicial, el proceso de devolución de un producto defectuoso, el proceso de funcionamiento de las escuelas, etc. Por tanto, la retórica procedural es idónea para desvelar el funcionamiento de cualquier proceso por una simple adecuación entre la lógica de los sistemas reales basados en procesos y la lógica interna y procedural de los lenguajes de programación sobre los que se sustentan los videojuegos. En consecuencia, la retórica procedural proporciona una forma nueva de hacer afirmaciones sobre el funcionamiento de los procesos que rigen la actividad humana.

Bogost describe el papel del jugador en la lógica de un videojuego procedural apoyándose en el símil de un silogismo truncado o entimema. Un silogismo truncado es aquel que evita alguna de sus premisas sencillamente porque su ausencia no afecta a su comprensión. Así, el silogismo "Sócrates es un hombre, Sócrates es mortal", elude la premisa mayor o regla general en la que se indica que "Todos los hombres son mortales" en virtud de su obviedad o, dicho de otro modo, porque su clausura es competencia del receptor. En el caso de un videojuego, corresponde al diseñador esconder el mensaje para que éste pueda ser desvelado por el jugador en el acto de jugar. En cualquier caso, para que la simulación del proceso pueda llevarse a cabo con garantías de éxito, el juego debe superar lo que Bogost denomina Simulation Fever. La cultura de la simulación ha desencadenado ciertas reacciones hacia las obras simuladas. Por un lado, la renuncia de la simulación supone una aceptación ciega de 
cualquier simulación aunque sea defectuosa; por otro, la negación de la simulación es el rechazo de la simulación por su naturaleza de réplica (Turkle, 1997). El auténtico valor de la simulación surge cuando se superan estas reacciones: "A simulation is the gap between the rule-based representation of a source system and a user's subjectivity" (Bogost, 107).

Por tanto, los juegos procedurales de Molleindustria esconden el auténtico significado del juego detrás de su estructura de entimema. Es en el acto de jugar cuando el jugador descubre, mediante el uso de las mecánicas, que hay un mensaje escondido en el juego; cuando éste le es desvelado, el jugador puede contemplar el mundo ficcional desde una óptica diferente, habitualmente bastante crítica y con pretensiones realistas. Este uso crítico y realista para desenmascarar una determinada realidad, nos recuerda al del neorrealismo, un cine marcado críticamente por una ideología marxista que pretendía despertar en el espectador otra conciencia sobre la realidad. Curiosamente, tanto el movimiento cinematográfico como el colectivo Molleindustria son italianos y ambos niegan, al principio de sus discursos, la realidad alternativa que presentan. Esta renuncia explícita a los mundos de ficción alternativos erigidos en sus obras, quizás por una cuestión de supervivencia en un mundo política, ideológica y económicamente correcto, no deja de resultar curiosa y, paradójicamente, un acicate para su visión de los hechos si entendemos que su intención es puramente irónica, es decir, contraria a lo que realmente los creadores sienten.

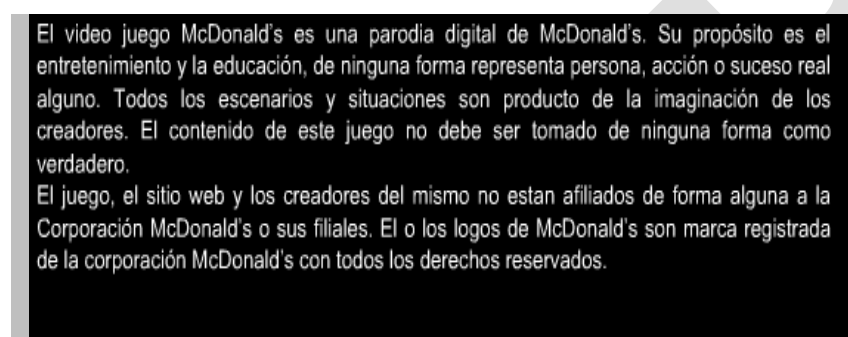

Figura 1. Negación del mundo ficcional alternativo de McDonald's Videogame (Molleindustria, 2006)

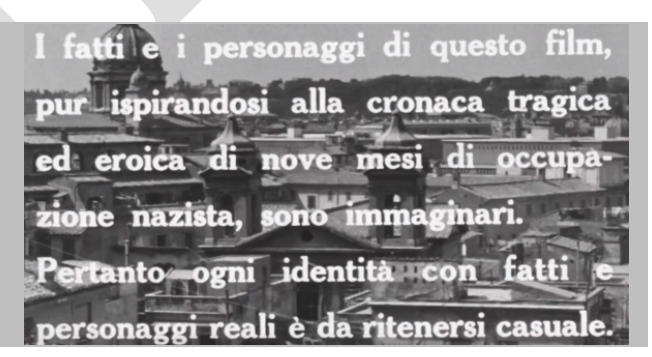

Figura 2. Negación del mundo alternativo de Roma, città aperta (Rossellini, 1945)

Por tanto, la saturación contingente de este mundo ficcional y la repentina culminación de su proceso de anagnórisis son dos fenómenos simultáneos que dependen del jugador. Por contingente queremos decir que es un hecho que puede suceder o no en función de cada usuario, aunque siempre, tarde o temprano, incluso en casos graves de incapacidad para creer en la existencia de mundos alternativos, la saturación llegará y la anagnórisis se habrá completado. En ese momento, lo que el jugador descubre, mediante un salto inter-mundo, es la realidad subyacente a todo modelo empresarial capitalista. A continuación, desvelamos la estructura de entimema del mundo ficcional natural propuesto en el resumen inicial que abre este apartado y la estructura de entimema del mundo ficcional natural alternativo que el jugador descubrirá durante el acto del juego. Recordemos que lo que el jugador descubre en acto de jugar es la regla general, oculta por el diseñador del juego. 
Regla- Las multinacionales de comida rápida deslocalizan su producción y deben gestionar múltiples procesos simultáneamente que implican el trabajo de numerosas personas en diferentes sectores productivos.

Caso-McDonald's es una multinacional de comida rápida.

Resultado- Luego McDonald's deslocaliza su producción y debe gestionar múltiples procesos simultáneamente que implican el trabajo de numerosas personas en diferentes sectores productivos.

Tabla 7. Silogismo inicial del mundo ficcional natural en McDonald's Videogame

Regla- Las multinacionales de comida rápida deslocalizan su producción en terceros países y deben gestionar múltiples procesos que terminan interfiriendo en la economía de estos, habitualmente en desarrollo, y en la deforestación de sus bosques; además, manipulan genéticamente los cultivos y la carne de vacuno para cubrir la demanda de sus clientes.

Caso- McDonald's es una multinacional de comida rápida.

Resultado- Luego, McDonald's deslocaliza su producción en terceros países y debe gestionar múltiples procesos que terminan interfiriendo en la economía de estos, habitualmente en desarrollo, y en la deforestación de sus bosques; además, manipula genéticamente los cultivos y la carne de vacuno para cubrir la demanda de sus clientes.

Tabla 8. Silogismo del mundo ficcional natural alternativo en McDonald's Videogame

\section{Mundos de ficción no revelados}

El campo de análisis de los videojuegos de mundos de ficción no revelados requiere ciertas aclaraciones preliminares. Si bien, como se ha visto, los mundos de ficción revelados implican una tendencia a la saturación, los que ahora nos ocupan solicitan un acercamiento inverso, fundado en la insaturación de las lógicas intensionales. Esto es, lo que promueve la relación del testigo con el mundo es un cierto grado de indeterminación que hace imposible completar su conocimiento sobre este. Esta particularidad arroja una mayor complejidad en la fórmula analítica, dada la singularidad interactiva del medio: si bien la fórmula de saturación presuponía las reglas como una herramienta integrada en la lógica epistémica del mundo, haciéndolas coincidir con el carácter "dado" de los géneros (VargasIglesias, 2018) y así invisibilizándola de cara a completar el juego, la de insaturación revela la necesidad de una distinción fundamental en el régimen diegético del juego, en dos modalidades narrativas: una epistémica -la del mundo ofrecido- y una deóntica-la de la regla demandada-. De este modo, lo que antes, en tanto que régimen diegético, se manifestaba como una sola modalidad epistémica que no ofrecía distinción textural entre mundo y regla, en este caso se ve escindido en dos modalidades en relación dinámica, cada una con sus particularidades texturales.

Asimismo, debe asumirse que en la insaturación rige un mecanismo lógico inverso a la saturación: si la segunda era mayor cuanto más dependiera del programa determinado por el juego, la primera crece en relación proporcional a la dependencia que la anagnórisis tiene respecto a la especificidad del jugador. Para la categorización de las distintas formas de insaturación se partirá, por tanto, de las mismas formas estructurales que sirvieron para definir los regímenes de saturación: programada, subjetiva y contingente, entendidas como predominio respectivo de las texturas explícita, implícita y cero. Los juegos a continuación analizados, Inside (Playdead, 2016), The Witness (Thekla, 
2016) y LSD: Dream Emulator (Asmik Ace Entertainment, 1998), siguen esa misma progresión hacia la falta de determinación del programa sobre la función del testigo.

\section{Mundos de ficción de insaturación programada. Inside}

Si bien videojuegos como Limbo (Playdead, 2010) y Little Nightmares (Tarsier Studios, 2017) presentan efectos de insaturación similares a los de Inside, se ha elegido este título como recordatorio de que no es necesaria una oposición radical a las condiciones del mundo natural para que pueda hablarse de un predominio epistémico de la textura cero. En el título que nos ocupa, que narra en sidecrolling la huida adelante de un niño en una aterradora sociedad distópica, nada que resulte ajeno a la regla queda explicado; de esa forma se suceden situaciones cuya lógica más inmediata ha de ser comprendida por el jugador, pero cuyo contexto se hurta de forma total a este en tanto que testigo del mundo: los sujetos convertidos en marionetas merced a una distópica tecnología de control mental, las criaturas acuáticas humanoides de largo y espeso cabello negro reacias a las fuentes de luz, los abrumadores sistemas de vigilancia, la ruinosa condición del mundo, el aberrante organismo rebosante de piernas, torsos y brazos que asume la función de avatar en el segmento final, nada se especifica sobre un contexto que vaya más allá de su entidad de regla, de suma de dificultades que sincopan la huida del niño protagonista. La Red se llena de hipótesis de usuarios sobre las posibles circunstancias sociales, políticas y tecnológicas que cohesionan el universo del juego, pero estas hipótesis no podrán trascender nunca su condición de tales porque no existe forma de contrastarlas. En términos epistémicos, el mundo que representa Inside es casi completamente irrecuperable.

Por su parte la modalidad deóntica, relativa a la regla, presenta una textura explícita, esto es, su aplicación sigue una función lineal de retos a desbloquear, de modo que no puede resolverse un reto $b$ $\sin$ haber resuelto antes un reto $a$. La elucubración de las resoluciones de puzles que se plantea sigue por tanto, y a pesar de la apariencia fluida del juego, un sistema de fases. Así, como indica la siguiente tabla, puede identificarse en este caso que la insaturación programada proviene de una suma de las modalidades epistémica contingente y deóntica programada.

\section{Modalidad epistémica contingente: prevalece la textura cero}

\section{Insaturación programada}

Modalidad deóntica programada: prevalece la textura explícita

\section{Tabla 9. Insaturación programada}

Definimos por tanto como de insaturación programada aquella forma videolúdica en la que la característica incógnita del mundo representado es el correlato de una dimensión programada de la 
regla. La saturación del mundo queda irresuelta del lado epistémico, pero no del lado deóntico, de ahí que pueda hablarse de un juego progresivo a pesar de su cualidad insaturada.

\section{Mundos de ficción de insaturación subjetiva. The Witness}

El caso de The Witness presenta un interesante contraste con el de Inside. Concebido por su creador, Jonathan Blow, como un gigantesco puzle con aspiraciones metafísicas, la localización de este first person puzzle en una isla en la que hay que resolver enigmas diseminados en una compleja estructura tecnológica por una inteligencia no declarada remite inevitablemente al imaginario de la serie Perdidos (Lost, ABC, 2004-2010), un clásico ejemplo de mundo de ficción cuyo rendimiento narrativo se da sobre la base de aquello que no es revelado. En el caso de The Witness, al igual que en Inside, la modalidad epistémica resulta contingente, e incluso, merced al carácter abstracto de los numerosos puzles a resolver, puede llegar a resultar innecesaria. En cualquier caso, tal juicio corresponde al jugador-testigo de forma individual, ya que en lo textual el mundo representado no es epistémicamente recuperable.

En cambio, la modalidad deóntica presenta en este caso una facultad que la convierte a una forma subjetiva: el diseño del sistema de puzles no es de acceso secuencial, sino aleatorio. El jugador puede iniciar los puzles en el orden que desee, así como, una vez iniciados, abandonarlos antes de su resolución para comenzar otros. La no-linealidad de este diseño presenta no obstante un inconveniente, y es que algunos acertijos no pueden ser resueltos si no se ha desarrollado cierta lógica en otros: en otras palabras, ciertos puzles son de tal complejidad que necesitan de la función tutorial de fases previas para que su concepto sea siquiera atisbado. Sin embargo, el carácter previo de estas fases es incógnito; no se explicita más que en la dinámica de prueba-error ejecutada por el jugador, que ha de verse impelido a abandonar los puzles de mayor complejidad y a elegir otros cuando entiende que la información de que dispone es insuficiente para resolverlos.

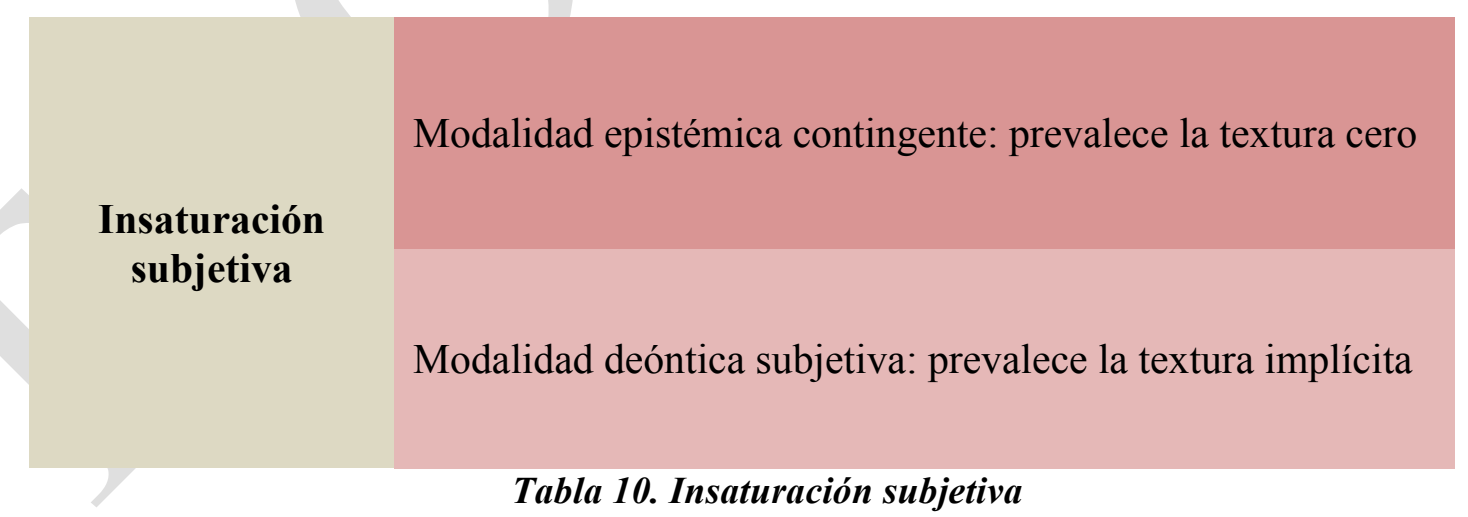

Así, la insaturación subjetiva define aquellos juegos en los que la textura implícita de unas reglas dispuestas con miras a una gran libertad de actuación del jugador se denomina en un mundo en el que predomina una textura cero, en la medida en que no se ofrece más contexto epistémico que aquel que 
haga posible la resolución del juego. Pueden encontrarse casos similares de este modo de insaturación en títulos como Braid (Number None, 2008) o The Talos Principle (Croteam, 2014).

\section{Mundos de ficción de insaturación contingente. LSD: Dream Emulator}

El caso de LSD: Dream Emulator supone una de las ocasiones más extremas en el amplio intervalo de posibilidades que ofrecen los mundos no revelados. Este juego japonés para Playstation 1, normalmente considerado el primer walking simulator de la historia, presenta la particularidad de que no satisface ninguna de las dos modalidades, epistémica y deóntica, cuyas coordenadas nos informan del tipo de mundo no revelado. Su contexto es totalmente silenciado y basado en una sucesión de escenarios de muy diferente condición, muchos de ellos, aunque no todos, en los márgenes de la psicodelia; del mismo modo, su sistema de reglas no es especificado en ningún momento, y el comportamiento de estas es tan aleatorio que es imposible fijar una hipótesis más allá de la especulación. La función del jugador-testigo, en primera persona, se limita al avance constante, con la excepción de que al colisionar con algunos objetos o transitar por determinados espacios se ve transportado a otro escenario mediante un fundido a color. Cuando el avatar fallece, normalmente por caer desde una considerable altura, aparece un panel con rasgos antropomórficos a cuyos lados figuran los términos "Upper", "Downer", "Static" y "Dynamic", y una casilla en el interior de este queda marcada en blanco.

De los jugadores depende interpretar en qué consiste este panel y qué define. Algunas hipótesis de usuarios en la Red aventuran que puede tratarse de una caracterización estadística del tipo de sueño que se ha tenido hasta su interrupción; sin embargo, ninguna explicación podrá trascender jamás el ámbito de lo meramente especulativo, porque no se ofrece en ningún caso una pista que pueda servir como contraste. Se trata de un juego-devenir en la acepción más estricta del término, una fantasía rizomática que produce sus derivas en términos tanto mecánicos como interpretativos.

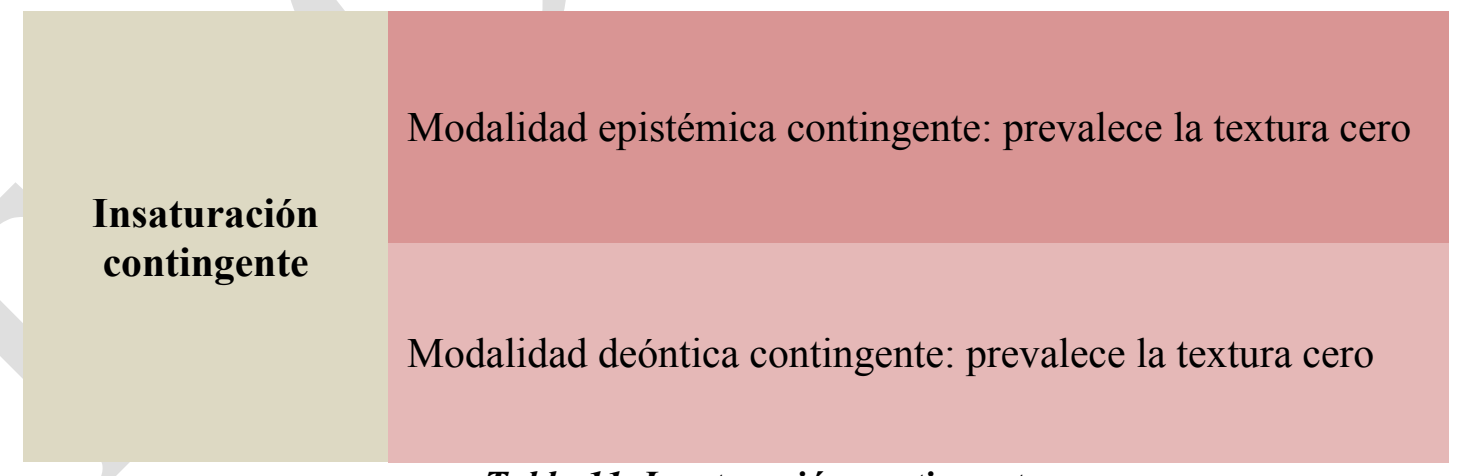

Tabla 11. Insaturación contingente

La insaturación contingente define así el tipo de mundo no revelado cuyos contextos epistémico y deóntico son plenamente hurtados y relegados al ámbito de lo interpretativo. Desde luego, tales casos pertenecen en su totalidad a un campo experimental que poco tiene que ver con el mainstream. Ejemplos como Black Lodge 2600 (Jak Locke, 2013), I'm Null (Mooosh, 2014) y The Tender Cut (No, 
thanks, 2015), todos desarrollados en un ámbito independiente, se encuadrarían en esta misma categoría.

\section{Conclusiones}

Este artículo se proponía alcanzar conclusiones estructurales sobre la construcción de mundos de ficción en el videojuego. Para ello se realizó una primera distinción entre mundos revelados y no revelados, considerando que esta representa un índice fundamental en la apreciación heurística del jugador-testigo respecto al mundo de ficción. En el caso de los videojuegos de mundo de fícción revelados, se encontró una clara coincidencia en la tendencia a la saturación intensional en la restricción narrativa epistémica, y una categorización de esta saturación en sus modalidades programada, subjetiva y contingente: la primera, caracterizada por un predominio de la textura explícita -es decir, aquella en la que la información se ofrece de forma lineal-, la segunda por un predominio de la textura implícita -es decir, aquella que remite a información recuperable en términos inferenciales, en la medida en que el jugador plantee su acceso a ella-, y la tercera por un predominio de la textura cero -es decir, la relativa al carácter irrecuperable de la información bajo cualquier circunstancia-. En este caso no se consideró la restricción deóntica -relativa a las reglas prescriptivas y de sanción- por hallarse integrada en cualquier aspecto de la restricción epistémica -relativa a las reglas culturales-: nada remite de forma específica al universo de las reglas que compone el juego, y estas se comportan de forma invisible respecto a sí mismas, siguiendo los códigos que son habituales a los géneros.

En el caso de los videojuegos de mundo de ficción no revelado se partió de una coincidencia en la insaturación intensional; a partir de esta categorización común, puede observarse como constante la modalidad epistémica contingente, y la categoría deóntica como variable reguladora de "extrañamiento" que comprende las tres variedades anteriormente señaladas, programada, subjetiva y contingente. En efecto, en este caso la restricción deóntica se independiza de la epistémica, siempre contingente, por cuanto la matiza con su consideración diferencial de las reglas prescriptivas del mundo de ficción.

Cabe destacar, no obstante, que la modalidad alética del mundo no revelado, relativa a las leyes naturales del mundo de ficción, puede llegar a influir decisivamente en este grado de extrañamiento: en videojuegos como Memory of a Broken Dimension (XRA, en desarrollo), Dreamscape (ShiverGaming, 2013) o Antichamber (Demruth, 2013), los tres del género first person puzzle, el contexto alético es tan distorsionado o volátil respecto a las condiciones conocidas del mundo natural, incluso en su fisicidad más inmediata a la regla, que la modalidad deóntica, ya sea explícita o implícita, padece las consecuencias de tal distanciamiento. En el primer ejemplo, el mundo representado ha visto rota la cohesión de su realidad, y de este incidente resulta una distorsión que hace casi irreconocible el entorno, dificultando la identificación de los puzles a resolver. Dreamscape es otro ejemplo de esta misma cualidad de las modalidades aléticas: su mecánica consiste en sostener una esfera negra mientras se camina por un laberinto que muta en el fuera de campo del jugador-testigo. Antichamber 
por su parte presenta torsiones físicas no-euclidianas que también dificultan la resolución de los puzles desde la modalidad alética.

En conclusión, el presente estudio sienta bases estructurales que integran las modalidades narrativas de la teoría de mundos de ficción de Doležel y la realidad cibertextual e interactiva del videojuego. Con ello se promueve la combinación, normalmente desatendida, de los términos propios de la teoría ludológica con una realidad narratológica que en definitiva es afín a todos los relatos. El videojuego demuestra no ser una excepción en este sentido, aunque sí en lo que respecta a la singularidad con la que agencia en su dispositivo su dúplice condición narrativa y cibernética.

\section{Bibliografía}

Aristóteles (1988). Poética. Trad. de Valentín García Yerba. Madrid, Editorial Gredos.

BATEMAN, C. (ed.) (2007). Game Writing Narrative Skills for Videogames. Boston MA, Course Technology.

Bogost, I. (2007). Persuasive Games: The Expressive Power of Videogames. Boston MA, MIT Press. DoležEl, L. (1999). Heterocósmica. Ficción y mundos posibles. Madrid, Arco/Libros.

Genette, G. (1989). Palimpsestos. La literatura en segundo grado. Madrid, Taurus.

Genvo, S. (2006). La game design de jeux vidéo. Approches de l'expression videoludique. Paris, L'Harmattan.

IsER, W. (1978). The Act of Reading: A Theory of Aesthetic Response. Baltimore, Johns Hopkins University Press.

Murray, J. H. (1997). Hamlet on the Holodeck: The Future of Narrative in Cyberspace. Cambridge MA, MIT Press.

Navarrete-Cardero, L., Pérez-Rufí, J. P., \& Gómez-Pérez, F. J. (2014). El pensamiento abductivo como fundamento ontológico de los videojuegos. Icono14, 12/2, pp. 416-440.

Planells, A. J. (2015). Videojuegos y mundos de ficción. Madrid, Cátedra.

Prope, V. (2014). Morfología del cuento. Madrid, Akal.

SCHAEFFER, J. M. (1999). Pourquoi la fiction? Paris, Seuil.

SCHELl, J. (2015). The Art of Game Design. Palm Beach, CRC Press.

TURKLE, S. (1997). Seeing through computers. The American Prospect, 8/31, pp. 76-82.

VArgas-Iglesias, J. J. (2018). Making Sense of Genre: The Logic of Video Game Genre Organization. Games and Culture. Online First, pp. 1-21.

Wolf, M. J. P. (2012). Building Imaginary Worlds. The Theory and History of Subcreation. New York, Routledge.

\section{Ludografía}

Asmik Ace Entertainment (1998). LSD: Dream Emulator. Sato, O. (director). Asmik Ace Entertainment. 
Croteam (2014). The Talos Principle. Hunski, D. (director). Devolver Digital, Bandai Namco. Demruth (2013). Antichamber. Bruce, A. (director). Demruth.

Frictional Games (2010). Amnesia: The Dark Descent. THQ, Frictional Games, Steam.

JAK LOCKE (2013). Black Lodge 2600. Locke, J. (director). Jak Locke.

Molleindustria (2006). McDonald's Videogame.

Mooosh (2014). I'm Null. Ayles, Z. (director). Mooosh.tv.

Naughty Dog (2013). The Last of Us. Straley, B., Druckmann, N. (directores). Sony Interactive Entertainment.

(2014). The Last of Us: Left Behind. Straley, B., Druckmann, N. (directores). Sony Interactive Entertainment.

Newsgaming (2003). September 12th. Frasca. G. (director). Newsgaming.

No, Thanks (2015). The Tender Cut. Kononenko, I., Kozhemyako, Y. (directores). No, thanks.

Number None (2008). Braid. Blow, J. (director). Number None, Microsoft Game Studios.

Playdead (2010). Limbo. Jensen, A. (director). Playdead, Microsoft Game Studios.

(2016). Inside. Jensen, A. (director). Playdead.

Shivergaming (2013). Dreamscape. ShiverGaming.

TANGo GAMEWorks (2014). The Evil Within. Mikami, S. (director). Bethesda Softworks.

(2015). The Evil Within: The Assignment. Mikami, S. (director). Bethesda Softworks.

(2015). The Evil Within: The Consequence. Mikami, S. (director). Bethesda Softworks.

TARSIER STUdios (2017). Little Nightmares. Talajic, D. (director). Bandai Namco Entertainment.

TheKLA (2016). The Witness. Blow, J. (director). Thekla.

XRA (En desarrollo). Memory of a Broken Dimension. Hanson-White, E. (director) Steam.

\section{Filmografía}

ABC (2004-2010). Perdidos (Lost). Abrams, J. J., Lindelof, D. (creadores). EEUU: Bad Robot. Rossellini, R. (director). (1945). Roma, città aperta. Italia: Excelsa Film. 